International Journal of

Advanced Science and Convergence

\title{
FABRICATION OF FUZZY LOGIC CONTROLLER ON SPEECH LABORATORY SYSTEM USING AT89C2051 MICROCONTROLLER
}

\author{
Jerry I. Teleron \\ Department of Computer Engineering, University of Southern Philippines Foundation, Cebu City, Philippines
}

\begin{abstract}
Background/Objectives: Most colleges and universities in the Philippines consider acquiring a speech laboratory equipment a tough matter to manage due to the prices and after-sales support. Methods/Statistical analysis: Many speech laboratory equipments from abroad exist but would not serve for a long time, particularly in terms of durability and maintainability. Findings: The researcher developed a digital innovation in developing speech laboratory equipment that suitable for the end-user to operate the system quickly using a personal computer (PC). An interface was connecting serial communication via USB port to a Fuzzy Logic Controller to facilitate the switching of speaker and microphone in the student cubicles/headsets in real audio while in peer-to-peer communication. Moreover, the monitor or console of the teacher operates in a more comfortable and user-friendly manner. When the teacher clicks the desired function or button, the Fuzzy Logic Controller module responds and processes the command to enable or disable the student's headset. On the student's side, there is a call button function to highlight the teacher console. Improvements/Applications: Hence, the system is maintainable and flexible that can even run on Windows Operating Systems and Linux.
\end{abstract}

\section{Index Terms}

Digital Innovation, Embedded System, Fabrication, Fuzzy Logic Controller, Microcontroller

\author{
Corresponding author : J. I. Teleron \\ jiteleron@uspf.edu.ph \\ - Manuscript received April 17, 2020. \\ - Revised June 2, 2020 ; Accepted June 20, 2020. \\ - Date of publication June 30, 2020.
}

(c) The Academic Society of Convergence Science Inc.

2619-8150 ( 2020 IJASC. Personal use is permitted, but republication/redistribution requires IJASC permission. 


\section{INTRODUCTION}

The Commission on Higher Education (CHED) [4], [13], [14] requires a speech laboratory equipment for all colleges and universities that offer Bachelor's degree programs to enhance students' speech and oral communication skills. Many colleges and universities cannot afford to purchase branded equipment because they are expensive [5]. More so, many schools are obtaining a localized speech laboratory which is created by an electronics technician or engineer [7]. Many teachers find it challenging to maneuver the device because of multiple switches and buttons to control [11]. The overuse of these types of devices can easily result in damage [10]. Also, their device cannot provide excellent audio quality.

A lot of speech laboratory equipment purchased abroad are also analog types [11]. The speech teachers find it difficult to control the device because of multiple buttons and switches to control [11]. There are available digitized speech laboratory systems, but they are also expensive and hard to maintain [5]. Schools have difficulty maintaining the equipment as there is no after-sales service [6][8]. Another means of installing a speech laboratory system is to establish an individual computer for each cubicle, which linked through a networking system with Voice over Internet Protocol (VoIP). Wherein the server controls every connected computer with software running in the host/server [8]. However, this type of speech laboratory system is also expensive, and most school owners reject it.

For these reasons, the researcher developed a [1] [327-329] Fuzzy Logic Controller to hold in the switching of the audio digitally using a stand-alone microcontroller-based system that caters digital switching on and off of the student's headsets. A desktop computer interface is connected to the computer via a universal serial bus (USB) for easy manipulation by the teacher. Hence, third-party software needed as a device driver for USB to RS232 converter [12].

On the desktop view, VisualBasic.net developed to support the connection between the two devices: the desktop PC and the Fuzzy Logic Controller [13]. The audio comes from the microphone input mixer that accepts a coil type microphone inputs feed into the Fuzzy Logic Controller that is held by the instructor [14]. A public address audio amplifier is also required to amplify the audio suitable for multiple headsets installed in the students' cubicles [15]. Fig. 1 shows the conceptual framework of the study.

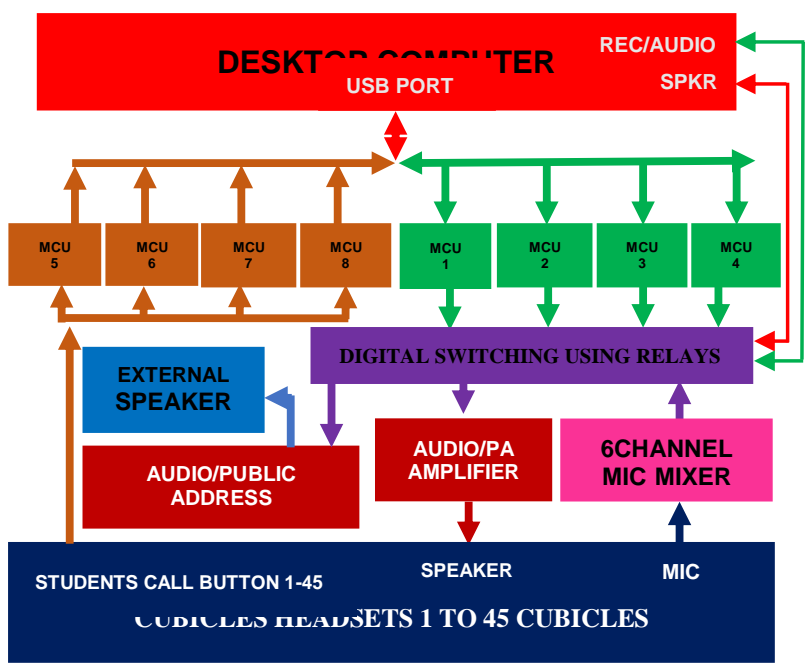

Fig. 1. Conceptual Framework of the study

\section{A. Objectives of the Study}

The ultimate objective of the study is to build another speech laboratory system different from other existing speech laboratory equipment. To make it easier and hassle-free for teachers handling speech subjects using a PC-Based console that specifies monitor/screen as a console by the teacher for the actual arrangement of the cubicle for the student.

Specifically, this study focused on the following: 1. Design and Fabrication of a Fuzzy Logic Controller interfaced connected to the desktop computer as the central console to control the students/cubicle headset. 2. Testing its usefulness and adaptability that can keep running in many Windows Operating systems, including Linux.

\section{Methodology}

The researcher used the deductive approach in solving a complex query wherein Plan-Do-Check-Act (PDCA) criteria were used as a model in finding a solution. After gathering all knowledge from different stages of planning, the researcher scrutinized the data and converted it to facts then postulated to come up with a tangible end-product. Fig. 2 shows the schema of the study.

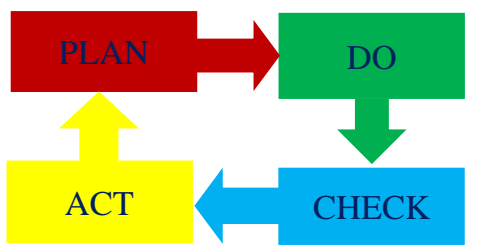

Fig 2. Schema of the Study 


\section{A. Plan}

The researcher used AT89C2051[16], a 2K bytes of memory microcontroller with a twenty-pin version of microcontroller suitable for small or even large applications. There are eight (8) microcontrollers (see Fig. 1) on the main system control panel to facilitate the control switching and call button of the forty-five (45) students or cubicles, connected into its serial communication port of each microcontroller [17].

Likewise, there were fifteen (15) information and yield programmable ports in one (1) microcontroller chip. There is a total of sixty (60) programmable ports in four (4) connected microcontrollers, namely; MCU1, MCU2, MCU3, MCU4, respectively. Fig. 3 shows the schematic chart of the microcontroller that is related to the hand-off switch. While MCU5, MCU6, MCU7, and MCU8 represent a forty-five call button for the students/cubicle. Fig. 4 shows the circuit diagram of the call button.

Furthermore, in Fig. 3, and Fig. 4, there were only one (1) microcontroller presented because the connection was the same for the other three (3) microcontrollers (See Fig.3), and in Fig. 4 with another three (3) microcontroller with similar connections, including all forty-five (45) relay switches. The Fuzzy Logic Controller synchronized the system, according to Fig. 1, presented in the conceptual framework.

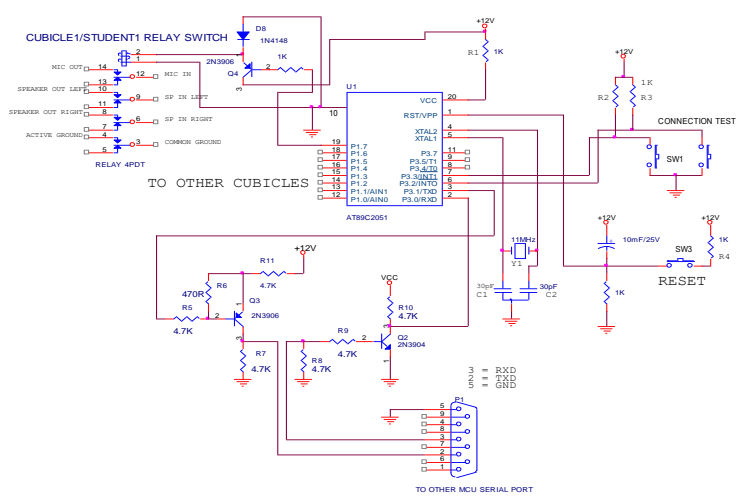

Fig. 3. Fuzzy Logic Controller Circuit Diagram

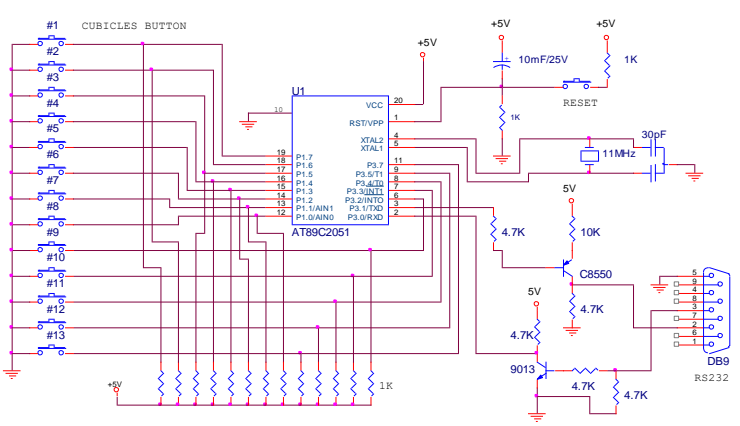

Fig. 4. Call Button Schematic Diagram

\section{Relay Switching Module}

The researcher separated the module for the digital switching of a Fuzzy Logic Controller by using multiple relays as a digital switch module that activates automatically when the microcontroller or Fuzzy Logic Controller receives serial data that is transmitted by the desktop computer [19]. Then, the teacher clicks the mouse to either enable or disable the button to activate or deactivate the microphone and the speaker of the headset and other all-important function buttons in the speech laboratory. Fig. 5, above depicts the circuit diagram of the digital switching module using a relay in three (3) cubicles only.

Then the teacher clicks the mouse to enable or disable the button to activate or deactivate the microphone and the speaker of the headset and all other essential function buttons in the speech laboratory.

\section{Power Supply}

The researcher also developed a power supply suitable for the power rating of the entire system. It uses a two-Amperes transformer as the main power supply and a regulator IC to determine the output potential. The power supply module appropriately designed so that it can withstand prolonged use [20]. It was tested for a long time to determine the integrity of the power supply. Fig. 6, shows the power supply modules schematic diagram of the system.
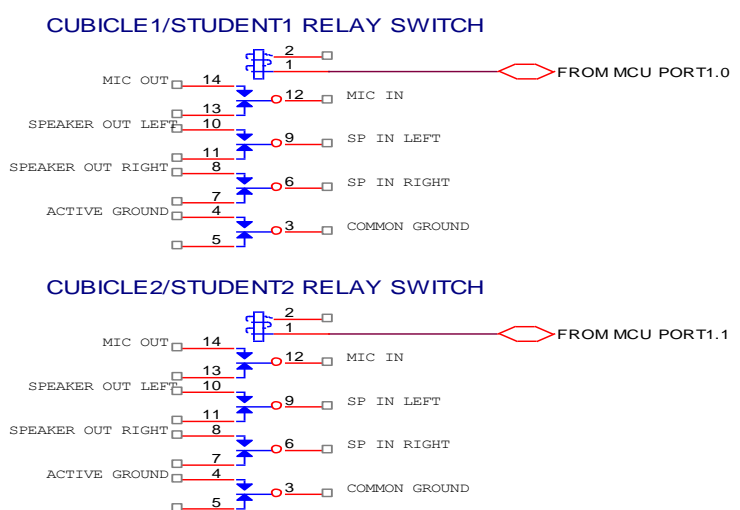

CUBICLE-n/STUDENT-n RELAY SWITCH

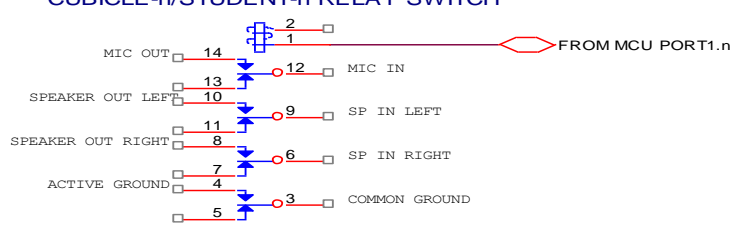

Fig. 5. Digital Switching Using Relay 


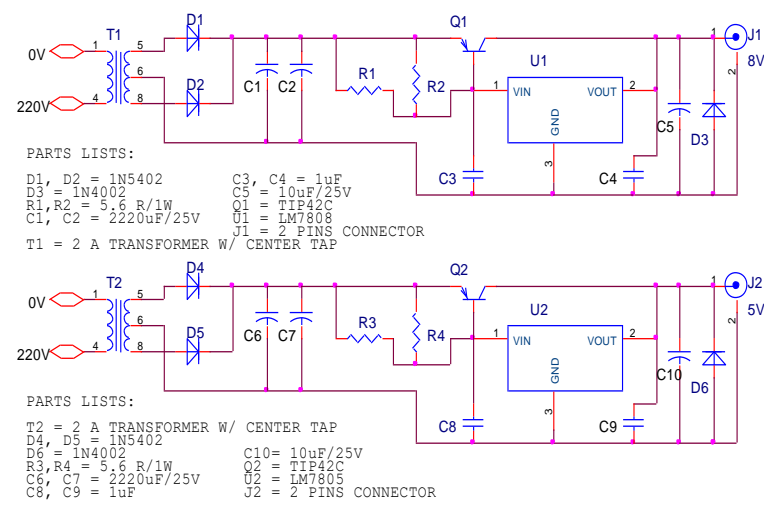

Fig. 6. Power Supply of the Fuzzy Logic Controller

\section{B. Do}

\section{Layout}

The researcher cited the importance of the PCB layout, wherein it states that [3] Printed Circuit Board (PCB) is the official name used for these electrical sheets. Ever, PCBs created by experiencing a confusing technique of point-to-point wiring, and these circuits profoundly presented to disappointment or harm. After those progressively exact structure strategies built, they increasingly secure. More so, the researcher also determined to used Circuit Wizard software for the PCB layout of the Fuzzy Logic Controller and the power supply modules. Because it is proven to be a user-friendly electronic CAD software, after all, the researcher did not encounter any difficulty.

Also, the printed circuit board (PCB) was using a single-sided PCB to lessen the complexity [21]. Silkscreen used to transfer the layout of the printed circuit board finally. Fig. 7, 8, and 9 the PCB layout of the Fuzzy Logic Controller switching relay module and power supply module.

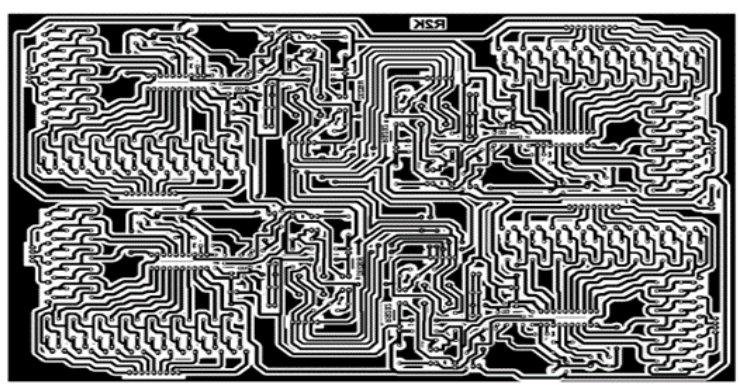

Fig. 7. PCB Layout of the Fuzzy Logic Controller

The size of the PCB layout of the Fuzzy Logic Controller almost the same as a short bond paper that is larger than the motherboard of a typical desktop computer. In which the researcher met many issues in transferring into the printed circuit board (PCB), another layout to the PCB for the relay modules with the same size of the Fuzzy Logic Controller. Fig. 8 shows the layout of the relay module and Fig. 9 power supply module.

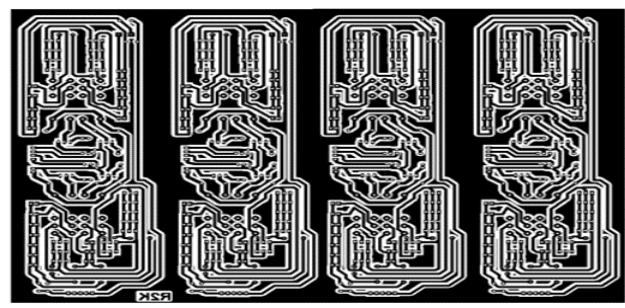

Fig. 8. Layout Relay Module

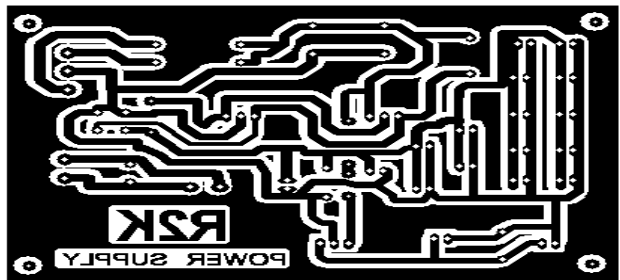

Fig. 9. Layout Power Supply Module

\section{Check}

\section{Assembly and Fabrication}

After creating a Fuzzy Logic Controller PCB, relay switching module PCB and power supply $\mathrm{PCB}$ are then placing of parts to the designated part number. Parts soldered carefully to avoid contamination to another track that can cause a short-circuit to the system that it may damage the components. Creating a front panel and back panel of the Fuzzy Logic Controller uses CorelDraw $\mathrm{x} 5$ version software to print it out in the large sticker and paste it to the steel chassis and drilling the holes to the desired position of the microphone and a speaker jack for the microphone input and speaker output. Fig. 10 shows the finished product of the Fuzzy Logic Controller device.

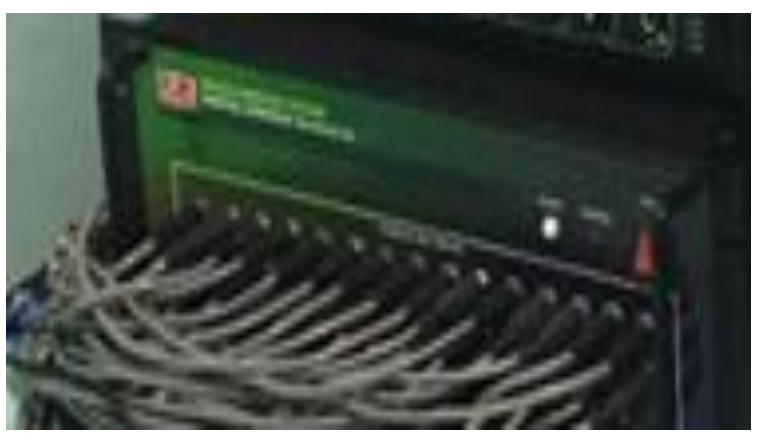

Fig. 10. Fuzzy Logic Controller System 


\section{Act}

\section{System Testing}

The researchers were careful in testing the functionality of the system in a bare part without any chassis-mounted so that the troubleshooting can be made quickly before installing it to the final setup of the system. Wiring the entire modules to connect to their desired location was carefully done to the actual chassis for the finalization of the system.

Hence, there were two (2) codes created to set up a proper testing process. First, a code for the microcontroller using an assembly language program given by the instruction set of the Intel family microcontroller known as MCS51 instruction sets, a complex code to communicate serially the eight microcontrollers installed in the Fuzzy Logic Controller. Second, codes were made in Visual Basic.net to test the connected part of the two devices if the connection established before doing the final coding process to finalize the testing procedure. Fig. 11 shows the test form screen for testing purposes only.

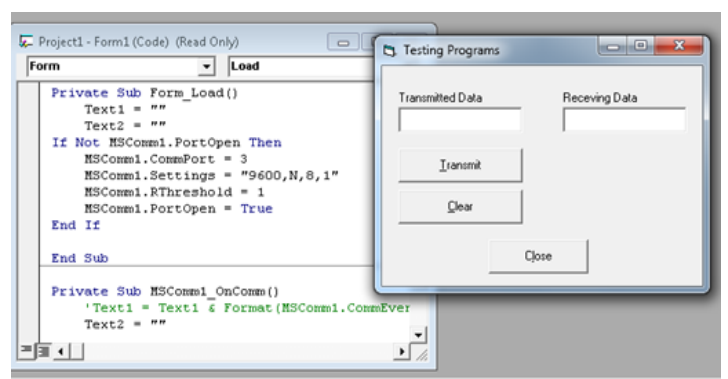

Fig. 11. Testing form screen VB.net Language

Finally, showing the connections of the two (2) devices, the desktop PC and the Fuzzy Logic Controller, the researcher continued to make a code to come upward with the desired end product of the system.

The researcher made several changes in the codes before the functionality finalized. The device tested after to note if it works. Fig. 12 shows a receiving code from assembly language at Raisonance IDE (RIDE) environment compiler software.

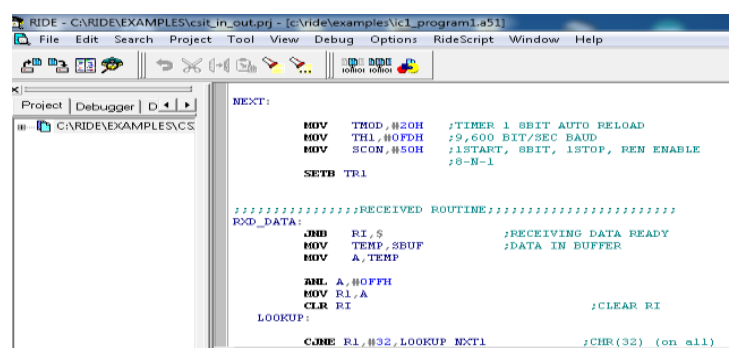

Fig. 12. Receiving Code Embedded in Microcontroller chip

\section{RESULTS AND DISCUSSIONS}

The researcher finally came up with the desired end-product. Fig. 13 shows how to unfold gradually and how the system is running in the desktop computer as the central controller or console for the teacher to operate a more comfortable and userfriendly system.

When the teacher clicked the desired function, the Fuzzy Logic Controller module responds and processes the command, like enabling/disabling the students' headsets. Fig. 14 shows the Fuzzy Logic Controller on Speech Laboratory System Using AT89C2051 Microcontroller that is manipulated by the teacher during operation.

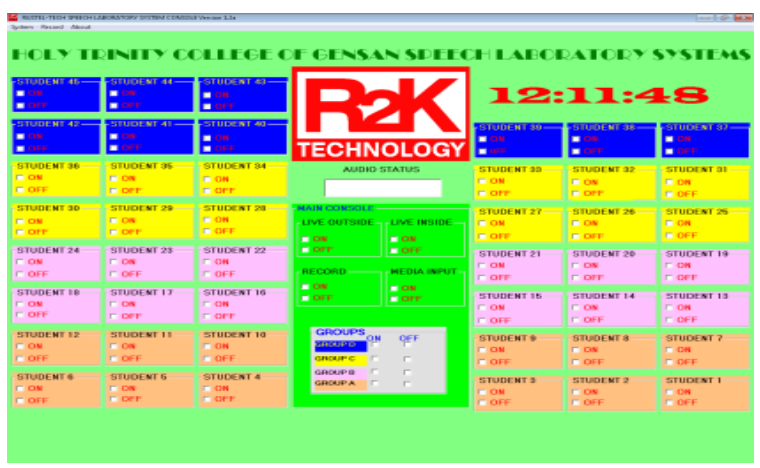

Fig. 13. Main Form Screen of Desktop Computer

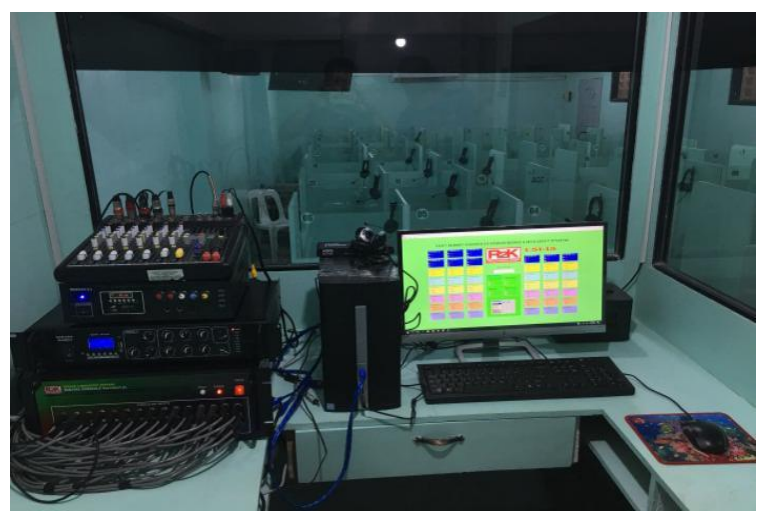

Fig. 14. Fuzzy Logic Controller on Speech Laboratory System

The main form or screen of the desktop computer was the console of the teacher wherein the real setup and numbering of the cubicles are shown in the primary form monitor or display to locate the places of each student quickly (See Fig. 13). The teacher operates the machine in a user-friendly manner because everything manipulated by the mouse, especially the essential operation of the speech laboratory-like listening to the individual student or group or even broadcasting without using a headset. Everything was made by just clicking the mouse in the desired command button. Also, while talking to the students, the teacher can record the conversation by 
clicking the RECORD check button to enable audio recording of the computer, saving the conversation, and can be played back as well using surround amplifier or to the selected target student. The student cubicle/console shown in Fig 15. The student cubicle control panel consists of a call button, a mic in, a speaker out, and volume control to the headset when the call button is press, the cubicle number of the PC monitor screen highlighted.

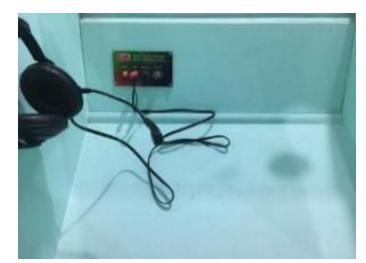

Fig. 15. Student/Cubicle Module

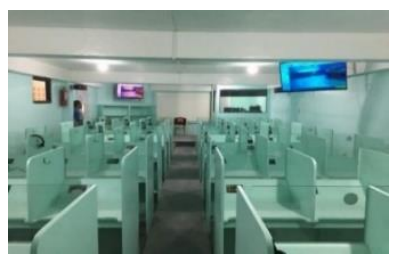

Fig. 16. Fuzzy Logic Speech Laboratory System

Also, the whole system revealed in Fig. 16 to visualize the actual Fuzzy Logic Controller on Speech Laboratory System Using AT89C2051 Microcontroller. It was proven and installed in one of the prominent schools/colleges in South Cotabato, particularly in General Santos City.

\section{Speech Laboratory in the Market}

At present, there are many existing speech laboratories in the market, but the designs are different because the researcher developed a conventional way of designing a solution. See Fig. 17, Fig. 18, Fig. 19, and Fig. 20, respectively, showing the big difference in its design and presentation of the entire settings. In Fig. 18 the University of Southern Philippines Foundation (USPF) acquired speech laboratory equipment from DY Multimedia Labs last 2005, and the setup was PC-Based, almost similar to Fuzzy Logic Controller. But it is a compact package proven difficult to repair due to all-in-one package including audio amplifier and microphone mixer. Also, on the main screen of the computer, there were many additional functions included in which the teacher was not comfortable to use, like audio recording to the external cassette tape recorder. (See Fig. 21, Fig. 22, Fig. 23) partially functional but needs to be repaired because of the many issues encountered by the teacher during laboratory operations.

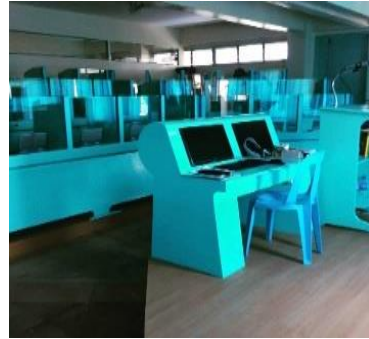

Fig. 17. VoIP Speech Labs
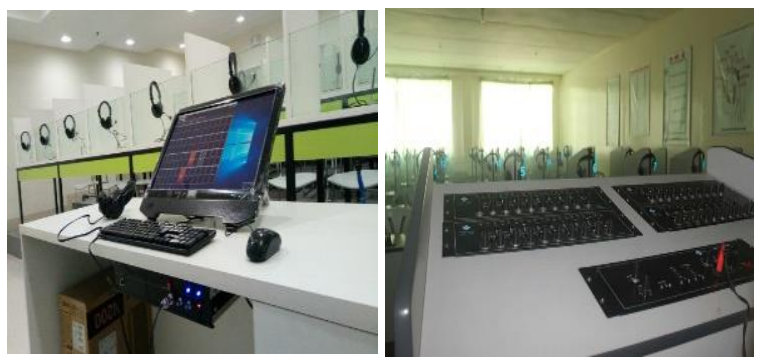

Fig. 19. Fully Computerized Fig. 20. Analog Speech Labs

It identified that the Fuzzy Logic Controller could be maintained by IT professionals, as presented in this paper because of the modular approach of developing the system. Another factor that the system is highly maintainable because it is included in the system software with a knowledge-based diagnostic and troubleshooting system when needed during troubleshooting. While the Fuzzy Logic Controller equipped with a diagnostic button to test the communication between the Fuzzy Logic Controller and the desktop computer communication connections.

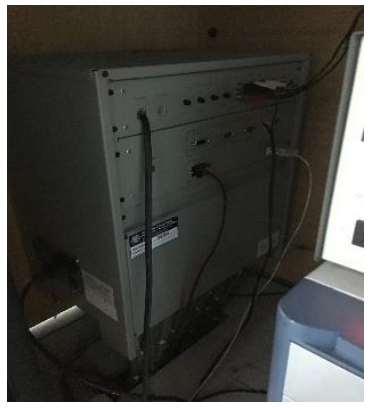

Fig. 21. Controller

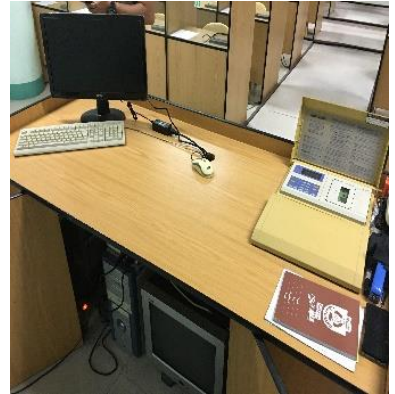

Fig. 22. Teacher Console 


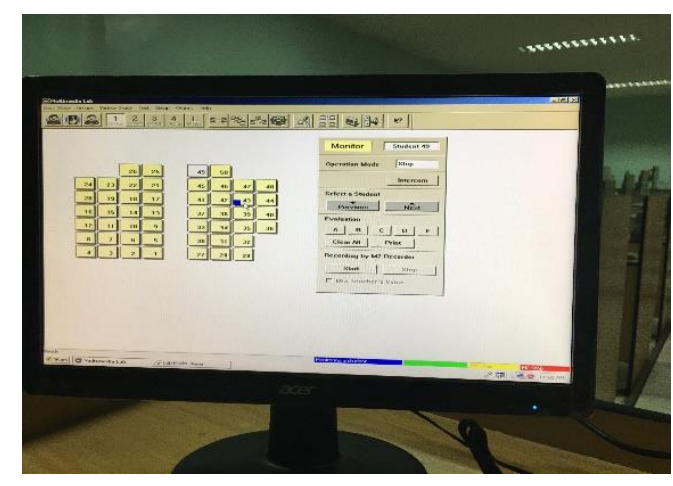

Fig. 23. Main Screen of DY Multimedia Speech Lab

\section{Functionality}

During the testing procedure, the researcher cited some studies of testing the compatibility of the operating system [2] that includes the system compatibility of different versions of Windows Operating Systems to test its flexibility. Table 1 shows the tabulated result of the testing process on various versions of the Operating System, including Linux.

In the progress of testing processes, the researcher discovered that the headset needs a protective system circuit to protect the speaker headsets when there is a sudden increase in volume in an audio amplifier setting. Fig. 24 shows the speaker protection circuit diagram installed in the student or cubicle headsets.

Table 1. Testing Environment Compatibility

\begin{tabular}{|l|c|c|}
\hline \multicolumn{1}{|c|}{ Operating Systems } & Compatibility & Functionality \\
\hline WINDOWS 7 & YES & YES \\
\hline WINDOWS 8.1 & YES & YES \\
\hline WINDOWS 10 & YES & YES \\
\hline LINUX & YES & YES \\
\hline
\end{tabular}

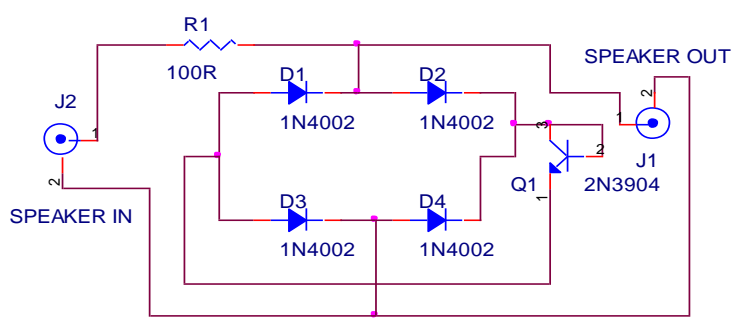

Fig. 24. Speaker Protection Circuit

Another testing procedure conducted to test its peer-to-peer communication capability by using serial communication between PC and Fuzzy Logic Controller during the actual operation of the speech laboratory controller. Table 2 shows the tabulated result.

Table 2. Peer-to-Peer Communication Testing Result BETWEEN PC AND FUZZY LOGIC CONTROLLER UNIT.

\begin{tabular}{|c|c|c|c|c|c|}
\hline $\begin{array}{l}\text { No. of } \\
\text { Trials }\end{array}$ & $\begin{array}{l}\text { PC main } \\
\text { form for } \\
\text { Students } \\
\text { Cubicle\# }\end{array}$ & $\begin{array}{l}\text { Teacher } \\
\text { Button } \\
\text { ON/OFF }\end{array}$ & $\begin{array}{c}\text { Cubicle } \\
\text { No \# }\end{array}$ & $\begin{array}{l}\text { MIC } \\
\text { Status }\end{array}$ & $\begin{array}{c}\text { Speaker } \\
\text { Status }\end{array}$ \\
\hline \multicolumn{3}{|c|}{ Desktop PC } & \multicolumn{3}{|c|}{ Fuzzy Logic Controller } \\
\hline 1 & 1 & $\mathrm{ON}$ & 1 & $\mathrm{ON}$ & $\mathrm{ON}$ \\
\hline 2 & 1 & OFF & 1 & OFF & OFF \\
\hline 3 & 2 & ON & 2 & ON & ON \\
\hline 4 & 2 & OFF & 2 & OFF & OFF \\
\hline 5 & 3 & $\mathrm{ON}$ & 3 & $\mathrm{ON}$ & $\mathrm{ON}$ \\
\hline 6 & 3 & OFF & 3 & OFF & OFF \\
\hline 7 & 4 & ON & 4 & ON & $\mathrm{ON}$ \\
\hline 8 & 4 & OFF & 4 & OFF & $\mathrm{OFF}$ \\
\hline 9 & 5 & $\mathrm{ON}$ & 5 & ON & ON \\
\hline 10 & 5 & OFF & 5 & OFF & $\mathrm{OFF}$ \\
\hline
\end{tabular}

Based on the results of Table 2, there were no errors encountered for every clicked on the command button by the teacher during the testing process. Meaning, the communication between desktop PC and Fuzzy Logic Controller was consistent and stable.

To understand further the result of testing, please refer to Fig. 13, the main form/screen of the system that serves as the console of the teacher. In general, the system was designed and ready for prolonged usage of operation without turning OFF the system. In this premise, the researcher knew how to create a functional circuitry in the serial communication controller, wherein it was fully isolated from any noise.

\section{SUMMARY, CONCLUSIONS, RECOMMENDATIONS}

Based on the results of the design and fabrication of a Fuzzy Logic Controller of Speech Laboratory System, Using AT89C2051 Microcontroller was found to be functional after a thorough testing process using different operating systems. After long hours of testing, the gadget found to be reliable, durable, and maintainable. Also, the spare parts are locally available in case a replacement is needed.

\section{Conclusion}

The researcher concludes that connecting two or more microcontroller via serial communication ports must follow the basic concepts of Data 
Communication by sending a valid code or ASCII code serially from point A to point B using synchronous or asynchronous transfer mode. Each microcontroller was programmed and embedded in its memory to perform a specific task. In the case of the Fuzzy Logic Controller, in Fig. 1, MCU1 and MCU5 controlled cubicles one(1) to thirteen (13), MCU2 and MCU6 controlled cubicles/students fourteen (14) to twenty-six (26), MCU3 and MCU7 controlled cubicles twenty-seven (27) to forty (40), while fortyone (41) to forty-five (45) and other functions like; GROUP, RECORD On/Off, EXTERNAL AUDIO In/Out On/Off controlled by MCU4 and MCU8. Thus, the teacher clicked the command button on the main screen form of the host PC, and the host PC sent a code to a respective MCU's to enable the student/cubicle headset. Therefore, it is a precise application of peer-to-peer communication wherein two (2) computers communicating with each other in a full-duplex mode.

Furthermore, the use of the AT89C2051 microcontroller was an acceptable practice in fabricating complicated applications because of the flexibility and strength of the chips, which can survive for a more extended time depending on the intent of the user.

More so, flexibility in the sense that the I/O port of a microcontroller can use as input or output. Therefore, the researcher appreciated the performance of the microcontroller in terms of designing and fabricating the Fuzzy Logic Controller on Speech Laboratory System wherein the system was built and functioning correctly after being installed in the laboratory room in the college of Mindanao. This state-of-the-art product was a perfect technopreneur scheme wherein the output of this research finds a sure possible to the product market, particularly for schools.

\section{Recommendations}

For the future development and betterment of this study, the researcher recommends the following:

1. Allow a personal display screen/LCD to the cubicles so that the students can view the article that is transmitted by the teacher instead of the big screen installed or centralized display in the speech laboratory room.

2. The provision of a wireless connection of the cubicle/student is possible instead of a wired connection. WIFI connectivity is better for easy installation and the use of the Internet of Things as an alternative. But there is no guarantee of a long time of usage.

3. Require an RF-ID reader to be installed at the entrance area to enable the automatic console/cubicle/student button on the desktop PC when the student enters the room.

At long last, the arrangement of the Fuzzy Logic Controller of Speech Laboratory System is adaptable that it very well may be balanced and planned dependent on the details or prerequisites of the customer.

\section{ACKNOWLEDGMENT}

The researcher expands his sincere appreciation and gratefulness to the individuals who helped him bring this development into reality.

To Engr. Alfredo B. Arenajo, the profound guide, and long-term friend for consistently giving prompts and backing in looking for after the energy for understanding this build-up of innovation.

To RUSTEL-TECH MARKETING, for trusting and allowing the researcher to developed their speech laboratory system as part of the implementation of the complete realization of the innovation.

To Dr. Odilon A. Maglasang, for sharing his valuable time in editing this paper.

To the researcher family, for the wholehearted support during the development of the entire system.

To Almighty God, for giving the researchers' knowledge and brilliant idea to make everything realized.

\section{REFERENCES}

[1] Zadeh, L.A. \& Rafik, A. A. (2018). Fuzzy Logic Theory and Applications: Part 1 \& 2, New Jersey, NJ: World Scientific.

[2] Computer Applications, Technology \& Engineering (2015). The journal for Integrated Computer Engineers of the Philippines

[3] Electrical Technology (2018). How to Test and Fix Printed Circuit Board (PCB) Defects? Retrieved from http://www.bit.ly/33FkAel

[4] CHED CMO 24 (2017). Policies Standards and Guidelines (PSG) for the Bachelor of Arts in English Language. Retrieved from http://www.bit.ly/2OWOsyG

[5] Marslab (2016). Speech Laboratory. Retrieved from https://marslabph.com/index.php/speechlaboratory/

[6] Alibaba (2019). Speech Laboratory Equipment. Retrieved from https://www.alibaba.com/showroom/languagelab-equipment.html

[7] Speech Laboratory Equipment (2019). Retrieved from 
https://www.facebook.com/speechlabcavite/?_t $\mathrm{n} \_$_ $=$HHH-R

[8] Bottomline Phonetic Speech Laboratory. (2018). Train your Students How to Become Communicative in English and Other Languages. Retrieved from https://www.bottomlinephoneticspeechlab.com/

[9] Speech Laboratory (Fully Computerized) (2017). Retrieved from https://www.mybenta.com/classified/77884/spee ch-laboratory-\%28fully-computerized $\% 29$

[10] Speech Laboratory (2019). Samar State University Retrieved from http://www.bit.ly/2BkCo22

[11] Peavey Electronics. (2019). FX 2 Series Mixers. Retrieved from https://peavey.com/fx-2-16channel-non-powered-mixer-with-usb-andeffects/p/03600940

[12] Prolific Technology Inc. (2012). USB to UART SERIAL/PRINTER. Retrieved from http://www.prolific.com.tw/US/ShowProduct.as px?pcid=41\&showlevel $=0041$

[13] Xanthium Enterprises (2019). Embedded Systems and Robotics for all. Retrieved from https://www.xanthium.in/

[14] P'B (2018). Circuit Today. Retrieved from http://www.bit.ly/35FL1T7

[15]P'B (2018). Circuit Today. Retrieved from http://www.bit.ly/33IZuvo

[16] Atmel Corporation (2018).8-bit Microcontroller with $2 \mathrm{~K}$ bytes Flash. Retrieved from http://ww1.microchip.com/downloads/en/Device Doc/doc3621.pdf

[17] Arm KEIL (2019). Peripheral Simulation. Retrieved from https://www.arm.com/products/developmenttools/embedded-and-software/keil-mdk

[18] P'B (2018). Circuit Today. Retrieved from http://www.bit.ly/2Mr7ETw

[19]ElectronicHub.org (2019). Types of Relays and Relay Driver Circuit. Retrieved from https://www.electronicshub.org/types-of-relaysand-relay-driver-circuit/

[20] Circuitstune (2019). 5V Regulated Power Supply Circuit Diagram. Retrieved from https://circuitdiagram.net/5v-regulated-solarcell-power-supply.html

[21] IndiaMart InterMesh Ltd. (2019). Single \& Double Printed Circuit Board Assembly. Retrieved from https://www.indiamart.com/proddetail/printedcircuit-board-assembly-15114799333.html 